\title{
The Functions of Visualization in Assisting Reading Comprehension among Young Learners
}

\author{
Masliza David, Nur Ainil Sulaiman
}

To Link this Article: http://dx.doi.org/10.6007/IJARBSS/v11-i10/10983

DOI:10.6007/IJARBSS/v11-i10/10983

Received: 03 August 2021, Revised: 26 August 2021, Accepted: 20 September 2021

Published Online: 04 October 2021

In-Text Citation: (David \& Sulaiman, 2021)

To Cite this Article: David, M., \& Sulaiman, N. A. (2021). The Functions of Visualization in Assisting Reading Comprehension among Young Learners. International Journal of Academic Research in Business and Social Sciences, 11(10), 68-79.

\section{Copyright: (c) 2021 The Author(s)}

Published by Human Resource Management Academic Research Society (www.hrmars.com)

This article is published under the Creative Commons Attribution (CC BY 4.0) license. Anyone may reproduce, distribute, translate and create derivative works of this article (for both commercial and non-commercial purposes), subject to full attribution to the original publication and authors. The full terms of this license may be seen at: http://creativecommons.org/licences/by/4.0/legalcode

\section{Vol. 11, No. 10, 2021, Pg. 68 - 79}

Full Terms \& Conditions of access and use can be found at http://hrmars.com/index.php/pages/detail/publication-ethics 


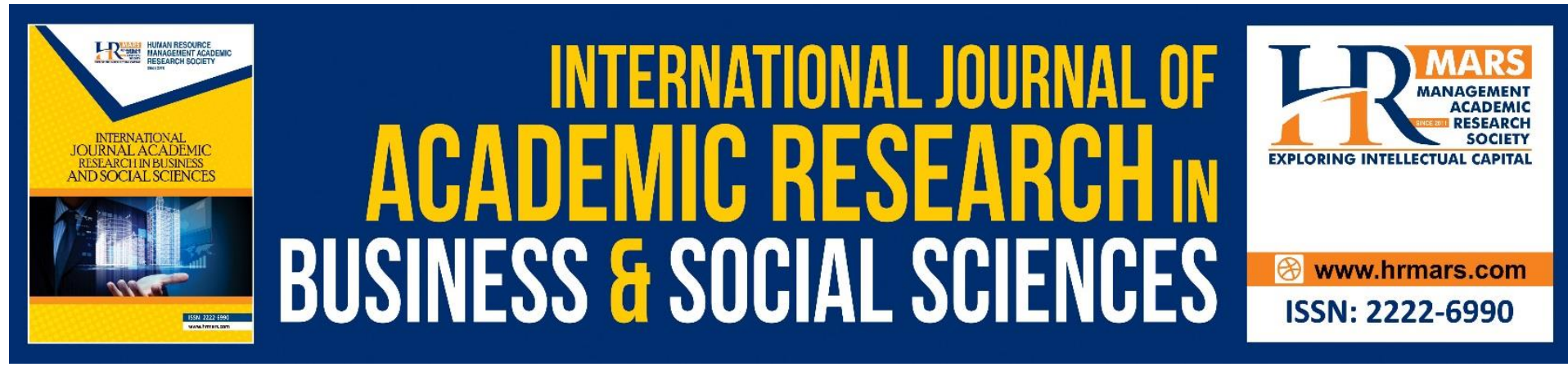

\title{
The Functions of Visualization in Assisting Reading Comprehension among Young Learners
}

\author{
Masliza David, Nur Ainil Sulaiman
}

Faculty of Education, Universiti Kebangsaan Malaysia (UKM), Bangi, Selangor, Malaysia.

\begin{abstract}
Reading comprehension determines the readers' level of understanding of a text. The process of comprehending a text requires meaning construction and the integration of the readers' knowledge, which are fairly challenging for learners of all ages especially young learners. As these crucial reading processes play major importance in reading comprehension, educators are applying a repertoire of reading comprehension strategies to guide young learners in reading. One of the strategies to have seen a significant impact in reading comprehension is visualization. However, not much literature discusses the visualization implementation by considering the aspects of the reading process. This paper, therefore, aims to explore the functions of visualization in assisting reading comprehension among young learners based on the aspects of the reading process. This paper will examine five functions of visualization based on the integration of eight aspects of the reading process in visualization application. This paper will be able to fill the gap in the literature by focusing on which reading process aspects are applied in different types of visualization. In particular, the significance of this paper is to assist teachers in looking through the visualization functions and how these functions impact reading comprehension for young learners.

Keywords: Visualization, Reading Comprehension, Young Learners, Function, Aspects Of The Reading Process
\end{abstract}

\section{Introduction}

The importance of reading comprehension as part of language development skills in learning is unquestionable. Reading is an important aspect of any educational process because it is required in all courses taught at all levels of the educational system (Cimmiyotti, 2013). Early introduction to reading and the need to expose the young learner to reading materials has been practised by parents and teachers at an early age. The need to expand the reading competency to text interaction proves reading is the starting point for more complex functions. Text interaction requires generating a cohesive and accurate text representation by considering processing speed, vocabulary ability, fluency, and decoding skill (Cutting et al., 2009). Text interaction supports engagement in reading which contributes to reading comprehension.

Reading comprehension, according to Clarke et al (2013), is made up of several skills and processes that are used to process information to understand the text rather than learning 
meaning from individual words or phrases. The crucial skills and processes involved to understand the text may not fully develop in young learners. Israel \& Duffy (2014) identified that young learners encounter vocabulary issues at word-level, semantics issues at the sentence level and lastly inference- making as well as comprehension-monitoring issues at the text level. Lack of vocabulary range in young learners is the primary problem of comprehension. For second language learners of English, the lack of vocabulary in L2 affects their comprehension. This is consistent with Bonk's (2000) findings that learners who understood less than $75 \%$ of a text's vocabulary had a difficult time comprehending it. This would later affect the secondary problem of semantics as young learners are unable to grasp the meaning being conveyed at the sentence level. These unstable foundations would make the act of connecting information from different parts of the text and making inferences from themes and main ideas at the text level a critical task for young learners. These issues are also proven as proposed by the Simple View of Reading, a theory on early reading comprehension, which states reading difficulties are rooted in two sources of variability; word reading and language comprehension (Oakhill, Cain \& Elbro, 2019).

In order to rectify the problem of reading comprehension, considering such difficulties faced by young learners in acquiring reading comprehension, a strategy proposed to aid the process is through visualization. Clay (1993) stated the importance of visual exploration, visual scanning and visual pick-up for young learners in reading but often dismissed by educators and researchers due to difficulty in observation as well as documentation. Visualization is one of the reading comprehension approach broadly used to overcome the reading comprehension issue. Visualization is the process of conjuring up actual or imagined thoughts in the mind's eye. It typically refers to visual images, noises, gestures, touch, taste, and smell, as well as any other images that can be interpreted or imagined by the human mind (Makarova, Makarova \& Varaksa, 2017). This productive process actively supports the reading process to construct understanding during reading activity. This process requires the combination of sensory sources and prior experience (Wood, 2002). Thus, text interaction occurs when the readers occasionally relate their experiences based on sensory integration as they try to ingest the content of the text. This paper, therefore, aims to explore the functions of visualization in assisting reading comprehension among young learners based on the aspects of the reading process.

\section{Definition and Types of Visualization}

In the classroom, visualization is utilised internally and externally. Internal visualization refers to visualizing textual information in the mind that is, forming mental nonverbal representations of the information described in a text (De Koning \& van der Schoot, 2013). Some of the activities include "make a picture on your head" instruction (Gambrell, 1982), forming metal images sentence-by-sentence (Clark et al. 1984) as well as read and form images as if watching "television in their head" (Hibbing \& Rankin-Erickson, 2003). Meanwhile, De Koning \& van der Schoot (2013) defined external visualization as nonverbal representations of text material found in the environment, such as a drawing that transforms text material into a nonverbal representation. This external visualization can be categorized into three types; reader-constructed, other-constructed and the combination of both. Reader-constructed is materials produced by the reader after reading a text to enhance their understanding while other-constructed refers to the additional visual form or external aids used by the teacher or instructor to support reading intact. Apart from producing a drawing, other researches extended on reader-constructed external visualization by using cut-out 
figures in visualizing narrative story events (Rubman \& Waters, 2000) and the use of webbased interactive visual strategy training 3D-Readers (Johnson-Glenberg, 2000).

\section{Reading Process}

In order to explore the functions of visualization in aiding reading comprehension among young learners, it is crucial to understand the aspects involve while young learners are reading. According to Roe, Smith \& Kolodziej (2019) reading process involves eight aspects namely sensory and perceptual, sequential, experiential, thinking, learning, association, affective and constructive as shown in Table 1.

Sensory and perceptual aspect is the basic step in perceiving materials presented to the reader. Sequential aspect in reading occurs when the reader can follow the patterns of words and grammar. Experiential aspect and association aspect share common importance of connectivity as the former entails when readers make use of their background knowledge to make the words meaningful while the latter link symbols, sounds, words and meaning. The thinking aspect is highly demanded in reading as readers must infer and analyse their reading. The learning aspect adds value and stacks new knowledge on existing ones. Finally, the affective aspect involves personal choice and attitudes in reading.

Table 1. Reading Process Aspects

\begin{tabular}{|l|l|}
\hline Reading Process Aspects & Elaboration \\
\hline Sensory and perceptual & $\begin{array}{l}\text { requires readers to perceive and analyse the symbols } \\
\text { placed in front of them }\end{array}$ \\
\hline Sequential & $\begin{array}{l}\text { involves when readers follow the sequence, or order, in } \\
\text { which reading material is arranged }\end{array}$ \\
\hline Experiential & $\begin{array}{l}\text { requires readers to relate words to personal experiences } \\
\text { to give them meaning }\end{array}$ \\
\hline Thinking & $\begin{array}{l}\text { demands readers to make inferences and analyse the } \\
\text { information }\end{array}$ \\
\hline Learning & $\begin{array}{l}\text { entails readers to recall what they have learnt in the past } \\
\text { and add new information and facts }\end{array}$ \\
\hline Association & $\begin{array}{l}\text { necessitates readers to recognize the links between } \\
\text { symbols and sounds, and between words and the } \\
\text { meanings they convey }\end{array}$ \\
\hline Affective & $\begin{array}{l}\text { expects readers to deal with personal preferences and } \\
\text { attitudes that influence the reading task }\end{array}$ \\
\hline Constructive & $\begin{array}{l}\text { obliges readers to make sense of the material by putting } \\
\text { everything together }\end{array}$ \\
\hline
\end{tabular}

Source: Adapted from Roe, Smith \& Kolodziej (2019)

\section{Conceptual Framework}

The eight aspects in the reading process elaborated by Roe, Smith \& Kolodziej (2019) above serves as the guideline in which the functions of visualization is applied. This study presents five functions of visualization in aiding reading comprehension and the integration of eight aspects of the reading process is elaborated in each of the visualization functions. As shown in Figure 1, the meaningful and personalising text connection function considers the sensory and perceptual aspect of the reading process to aid reading comprehension. The problemsolving characteristic function involves two aspects of the reading process namely 
experiential and learning. Thirdly, decorative and motivation elements function of visualization considers affective aspect in its application of reading activity. Sequential and thinking aspects of the reading process are highly utilized in promoting learning. Finally, the association aspect is integrated into comprehending and mastering tough content function. All five functions of visualization incorporate the aspect of the constructive reading process.

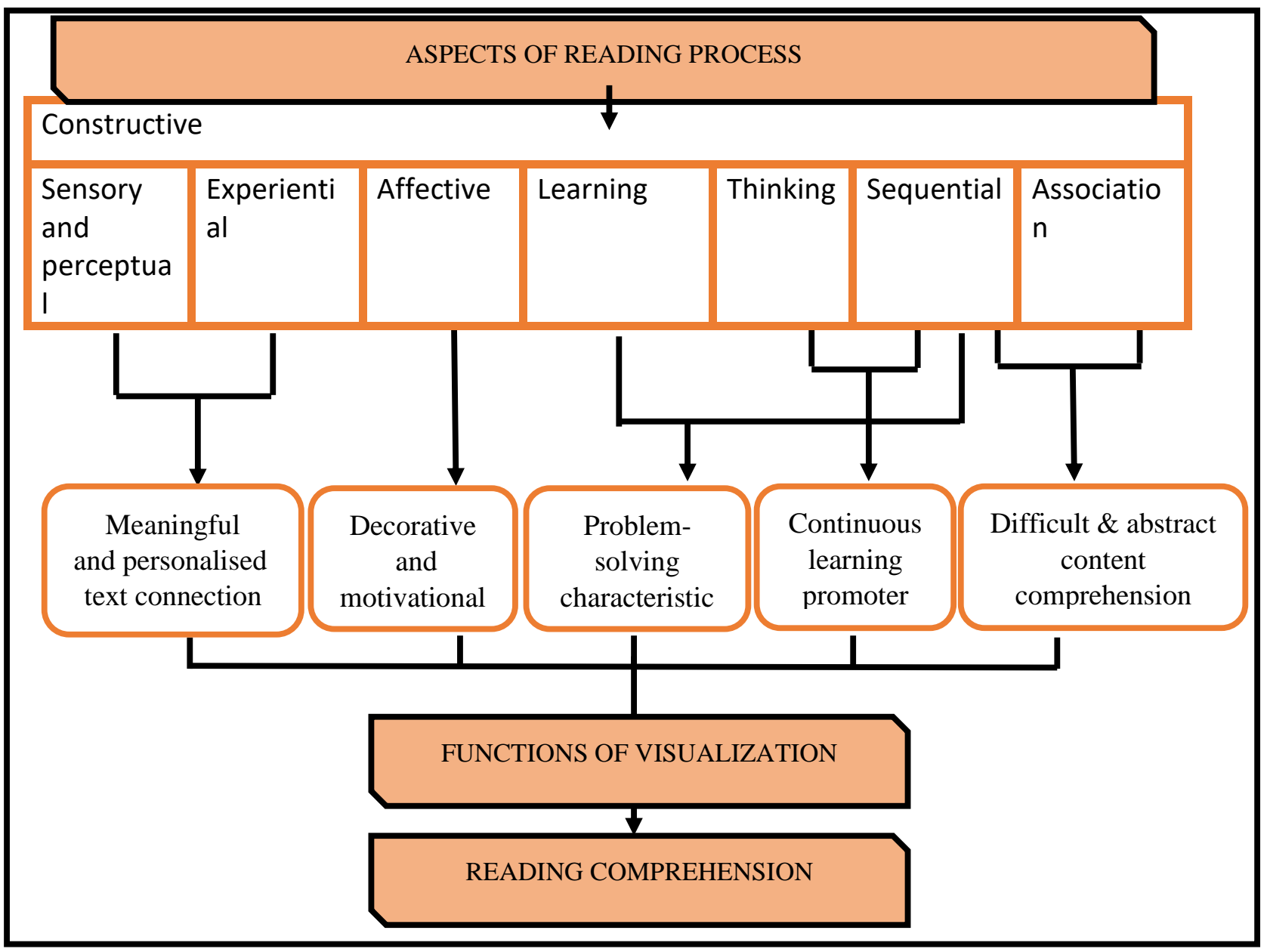

Figure 1: Conceptual Framework of Visualization Functions

\section{Meaningful and Personalised Text Connection}

Visualization has the ability to make a text more personal and meaningful to the young readers. This function of visualization takes into account the sensory and perceptual aspect of reading process. This role of visualization in assisting reading comprehension has been recognised by Sadoski (1985) who deduced that image elaborations are 'a means of personalising literary texts whilst also maintaining a core of shared meaning'. The process of visualization, be it external or internal, integrate sensory and perceptual aspect while reading. During reading, young learners use mental imagery to infer what is going on in the minds of the characters, to anticipate and justify their behaviours and feelings, which contributes to the mental model (Boerma, Mol \& Jolles, 2016). The details that are directly stated in the text, as well as the situational representation of storyline events such as the people, locations and actions, are assumed to be included in mental models. This information is coupled with the young learner's general knowledge of stories as well as the young learner's context knowledge of the story's subject. This is linked to the elements that contribute to meaningful 
and personalised reading which is the intensification of a sense of vividness via various sensory and/or affective involvement aspects (Mackey, 2019).

Apart from the sensory and perceptual aspect of reading process, this visualization function also webbed the experiential aspect of reading process. Visualization could offer young learners not only to see more clearly but also to feel more sharply. This will result in a clearer connection with the text through emotion and experience linkage. It is clear that visualisation is heavily reliant on prior knowledge, especially images from our contexts that are retained in our short and long-term memory and retrieved when necessary (Addinna, Ovilia \& Asfina, 2019). By making a connection between the young learner's prior knowledge and text meaning, young learners can personalise their reading process. This is also closely related to the principle of constructivism and experiential learning (Backhouse, Fitzpatrick, Hutchinson, Thandi \& Keenan, 2017; Naug, Colson \& Donner, 2016; Amin, 2020). Young learners constructively build their new understanding based on an existing idea and make use of their experience as the foundation. Through the learning combination of experience, perception, cognition and behaviour to make up a holistic integrative perspective in experiential learning (Kolb, 2014) with the creation of own meaning through experience (Aljohani, 2017), the process of visualization during reading would be more in-depth and the elements of visualization in producing a drawing would be utilized optimally.

\section{Decorative and Motivational}

Pictorial drawings can serve as a decorative and motivational element (Schnotz, 2002). This function is correlated with the affective aspect of the reading process which includes selfconcept, interest and attitudes. Poushaneh and Azar (2020) research proved the effect of mental imagery strategy instruction on the reading comprehension of EFL students. The learners were asked to freely create mental images before, during and after reading the summary of a short story. The learners later drew their mental images of the characters, scenes and locations in the story according to what they perceive. The findings reported that the mental imagery method, which is associated with the learner's ability and interests, have increased learners' motivation for reading comprehension and story reading. Besides mental imagery as a robust tool, the selective variability of the topics also contributes to the learner's active and eagerness to draw paintings of characters, objects and scenes from the story during the intervention.

The number of pictorial drawings used can be reduced or increased in reading materials as a motivational element of the affective aspect in the reading process. When the number of pictorial drawings is increased in reading material, pictorial drawings can retain readers' interest and reading motivation. Meanwhile, when the number of pictorial drawings is decreased in reading material, it could play interpretational function. According to Carney \& Levin (2002) in text processing, pictures provide four traditional functions namely decorative, representational, organisational, and interpretational while they sometimes carry transformational functions. Strategically positioned and economical illustration or pictorial drawings in the reading materials with the functions of representation or interpretational would train readers' mental visualization. This is crucial as the motivational elements are not only to encourage young learners to read but to further encourage the transition from illustrated reading materials to non-illustrated reading materials. This can be done with the practice of mental imagery based on the limited illustration given. Young learners migrating to non-illustrated books must be prepared to use their imaginations and what they've acquired through visual media and other sensory input to generate mental pictures and 
sensory images for characters, places, and narratives, as well as information offered in texts. As most reading materials with pictorial drawings carry one or more functions, they can enrich the young learners' mental imagery successfully. These motivational elements of reading materials can spark different types of mental imagery such as visual, auditory and motor (Ganis \& Schendan, 2011).

\section{Problem-solving Characteristic}

Creating a picture from reading material, as part of external visualization, is a form of problem-solving activity and this function emerges from the learning and sequential aspects of reading process. Throughout the process starting from reading to the production of the drawing, young learners will go through a series of steps. Since young learners must make multiple decisions before creating their final product, creating a picture is a method of problem-solving (Levstik and Barton, 2015). Free (2004) proved such function of visualization in the research conducted on the use of illustration analysis and reader-generated drawings to improve reading comprehension. The two main findings suggested that the researcherillustrated texts resulted in significantly higher reading comprehension than the unillustrated texts and the treatment of illustration drawing instruction to the learners also increased reading comprehension. This is observed through the more accurate answers given for inference and factual questions during the research. Free also further inquired on the development of guidelines to assist teachers to create text illustrations and instructions methods for learners to create effective drawing illustrations. The learners are engaged in multiple processes and encountered decision-making conditions while producing their illustrations.

The multiple processes and decision-making condition that learners are experiencing are the integration of the learning and sequential aspects of reading process while young learners generate their drawings as outlined in the Generative Theory of Drawing Construction (GTDC) and Cognitive Model of Drawing Construction (CMDC), in which young learners must select, organise and link before they can create. Young learners must first think of the details to be included in their drawing as they then organize the details from the text. They later transform the data into an image, bridging the gap between verbal and visual knowledge representations (Van Meter and Firetto, 2013; Schmidgall et al., 2018). By going through these steps, the teacher can observe the young learners' level of comprehension based on the selected details and the organization of ideas.

\section{Continuous Learning Promoter}

Another function of visualization that is developed from the thinking and sequential aspects of reading process is promoting continuous learning. Visualization does not stop at reading comprehension but promotes further learning (de Leur, Van Boxtel \& Wilschut, 2020). Visualization is not only a good starting strategy to encourage a deeper understanding of the text, but it can spark different activities to keep the learning continue. As it starts mentally, visualization can be made external and shared with others. A similar concept was applied in the R.I.D.E.R strategy to improve reading comprehension. R.I.D.E.R is a reading comprehension strategy that uses visual imagery to strengthen the pupils' comprehension monitoring ability and information recall. R.I.D.E.R strategy is the acronym of Read, Imagine, Describe, Evaluate and Repeat (Evriani, 2019). R.I.D.E.R strategy applied the concept of visualization where it promotes mental construction. R.I.D.E.R, according to Mercer and Mercer (2006) is a visual imagery method for reading comprehension that allows pupils to 
absorb the material and communicate it with a partner. R.I.D.E.R promotes the speaking activity in which learners share their mental pictures with their partners, groups or class after they have read the text. Such activity promotes discussion to expand learning and reading comprehension.

Discussion or presentation activity can happen when young learners are asked to describe their drawings to one another (Ainsworth, Prain \& Tytler, 2011). This involves the sequential aspect in the reading process when young learners need to arrange their ideas on how to describe their products to others. When young learner sequences their ideas and describes their product, they can enhance their understanding and impart their ideas to others. This is especially interesting for visualization prompts from unfamiliar everyday experiences. Therefore, young learners based their visual mental construction on countless variations of dreams, fantasy, memory and media and extract them through this collective imagination without personal experience (Brosch, 2018). Such sources of product building create variations and creativity which encourage further activity such as verbal presentation, writing or project-based materials.

Visualization has also been proven to aid as a writing planning activity. The consideration of the thinking aspect reading process would improve young learners' reading plans. Moore \& Caldwell (1993) compared two types of writing planning activities, drama and drawing, against discussion writing planning activity on 63 primary school pupils. The key findings reported that the drama and drawing groups continuously and considerably outperformed the control group in terms of writing quality. It is also important to link visualization to metacognition. Young learners should be conscious of their learning. Having visual tools would help them to monitor their cognitive activities by incorporating metacognitive techniques into their learning process, comprehend, memorise, track and correct errors, measure progress, and evaluate their outcomes (Makarova, Makarova \& Varaksa, 2017).

\section{Difficult and Abstract Content Comprehension}

Visual displays, in the form of other-construct external visualization, can assist in comprehending and mastering difficult content (Mayer, 1997). The two major aspects of reading process that contribute to this function of visualization are the sequential and association. In the case of young learners, fiction and non-fiction reading materials come with different sets of content difficulty levels. The combination of sequential and association aspects of the reading process can be inserted in the visualization function to tackle the issue of content difficulty. When Moriyanti, Muna and Ismail (2019) conducted their research on corroborating children's reading ability by connecting visualization and comprehension, they utilised passages without pictures for the control group and a passage with a sequential visualization strip for the experimental group. When the young learners were given reading test questions to analyse their reading sub-skill ability of main idea, details, vocabulary and inferring, the experimental group performed the more above-average score with inferring skill as the highest compared to the control group. The assistance of the sequential visualization strip, which integrates the sequential aspect of the reading process, was able to help young learners dissect the story and comprehend it bits by bits before making constructive understanding as a whole at the end.

Apart from difficult content, the young learners may experience reading materials with an abstract concept that makes description alone insufficient for understanding. This would increase the young learner's frequency of gazing at supplementary visual displays as the learning subject becomes more demanding (Carney \& Levin, 2002). Therefore, external 
visualization may also aid in the development of a mental image by clarifying implied or ambiguous relationships in the text (Eitel \& Scheiter, 2015). This is where the association aspect of the reading process is applied. Hibbing and Rankin-Erickson (2003) described how some pupils are perplexed by critical characteristics in the setting or spatial relationships between characters or items addressed in a text because they do not grasp them. It was discovered that a drawing or fast sketch created by the teachers is an effective tool for fostering knowledge. For example, when the pupils are reading about a natural disaster such as an earthquake and volcano eruption, the teacher might need to draw the two plates or two blocks of rocks that rubbing each other causing the release of seismic waves and how molten rock called magma was formed. Similar to how teacher-generated drawings assist pupils in visualizing the events or relationships in a text, pupils-generated drawing could also assist teachers in identifying what the pupils understand or do not understand from the text. As explained by Kendeou, Van Den Broek, Helder \& Karlsson (2014), two groups of reading comprehension cognitive processes are lower-level processes and higher-level processes. The lower level processes involve interpreting textual code into meaningful linguistic units while higher-level processes require merging these units into a meaningful and cohesive mental image. Visual displays such as illustration with the function of aiding the textual content helps readers to interpret the text better and contribute to the construction of meaning in higherlevel processes. For unsuccessful readers who experience challenges in lower-level processes such as decoding, reading fluency and vocabulary knowledge, visual displays would lighten the burden in the reading comprehension process. This is also supported by Lin (2020) in which a visual representation of the texts will be an excellent solution for supporting inefficient readers who lack adequate decoding skills.

\section{Conclusion}

As each function of visualization is discussed, it is unwise to reject the benefits of visualization in assisting reading comprehension. Visualization is able to address the young learner's reading issues detected at the word level, sentence level to text level. As discussed throughout this paper, visualization impacts reading comprehension better from the perspectives of its functions connected to the aspects of the reading process.

Firstly, the combination of sensory and perceptual aspects with the experiential aspect of reading together contribute to the visualization function of a meaningful and personalised text connection. The reading process through visualization would be intensified through various sensory and experience linkage. Secondly, the affective aspect of reading promotes the decorative and motivation function of visualization in aiding reading comprehension. Pictorial drawings can be used to retain young learners' interest, improve reading motivation, practise mental imagery and encourage the transition from illustrated reading materials to non-illustrated reading materials. Thirdly, learning and sequential aspects of reading are imparted through the visualization function of problem-solving characteristics. Young learner engages in multiple processes and encounters decision-making condition in which they need to select, organise and link before they can create their visualization product. Forth, sequential and thinking aspects of reading are incorporated in the continuous learning promotion function. Visualization activity does not limit its perimeter to reading skills alone but it can be expanded into speaking skill activity such as discussion and presentation as well as writing skill activity such as pre-writing and story expansion. Fifth and lastly, association and sequential aspects emerge in the difficult content comprehension function of visualization. The visual display can act as supplementary to clarify ambiguous relationships 
in a text. Apart from that, sequential visualization activity can help readers to dissect the content and make constructive understanding by comprehending bit by bit.

All of the visualization functions are affecting learners cognitive, affective and behaviour in reading. The functions put forward in this article can also benefit the learners in general learning as it functions across-curricular which in turn enhance the learning experience as a whole. Overall, these functions would benefit learners and educators in producing independent readers who are able to utilize the strategies taught when it is practised correctly since young. This added contribution to learners' metacognitive awareness would help learners to be critical readers and responsible learners. Producing future quality readers of younger generations should be the top priority of education and using decades of proven effective strategies to continue the successful results would direct the nation's education progress positively.

\section{References}

Addinna, A., Ovilia, R., \& Asfina, R. (2019). Students' Visualization in Reading and their Cognitive Learning Styles. Lingua Didaktika: Jurnal Bahasa dan Pembelajaran Bahasa, 13(1), 26-34.

Ainsworth, S., Prain, V., \& Tytler, R. (2011). Drawing to learn in science. Science, 333(6046), 1096-1097.

Aljohani, M. (2017). Principles of "constructivism" in foreign language teaching. Journal of Literature and Art Studies, 7(1), 97-107.

Amin, A. (2020). 'Drawing' to learn Anatomy: Exploring the theoretical underpinning and conditions favouring drawing based learning. JPMA. The Journal of the Pakistan Medical Association, 70(11), 2017-2022.

Backhouse, M., Fitzpatrick, M., Hutchinson, J., Thandi, C. S. \& Keenan, I.D. (2017). Improvements in anatomy knowledge when utilizing a novel cyclical "Observe-ReflectDraw-Edit-Repeat" learning process. Anat Sci Educ; 10: 7-22.

Boerma, I. E., Mol, S. E., \& Jolles, J. (2016). Reading pictures for story comprehension requires mental imagery skills. Frontiers in psychology, 7, 1630.

Brosch, R. (2018). What we 'see' when we read: Visualization and vividness in reading fictional narratives. Cortex, 105, 135-143.

Carney, R. N., \& Levin, J. R. (2002). Pictorial illustrations still improve students' learning from text. Educational psychology review, 14(1), 5-26.

Cimmiyoti, C. B. (2013). Impact of Reading Ability on Academic Performance at the primary level (Master's Theses, Capstones and culminating Projects, Dominican University of California). Retrieved from https://doi.org/10.33015/dominican.edu/2013.edu.18

Clark, F. L., Deshler, D. D., Schumaker, J. B., Alley, G. R., \&Warner, M. M. (1984). Visual imagery and self-questioning: strategies to improve comprehension of written material. Journal of Learning Disabilities, 17, 145-149.

Clarke, P. J., Truelove, E., Hulme, C., \& Snowling, M. J. (2013). Developing reading comprehension (Vol. 1). Chichester, UK: Wiley-Blackwell.

De Koning, B. B., \& Van der Schoot, M. (2013). Becoming part of the story! Refueling the interest in visualization strategies for reading comprehension. Educational Psychology Review, 25(2), 261-287.

De Leur, T., Van Boxtel, C., \& Wilschut, A. (2020). "When I'm drawing, I see pictures in my head.": secondary school students constructing an image of the past by means of a 
drawing task and a writing task. European Journal of Psychology of Education, 35(1), 155-175.

Eitel, A., \& Scheiter, K. (2015). Picture or text first? Explaining sequence effects when learning with pictures and text. Educ. Psychol.Rev. 27, 153-180.

Evriani, E. (2019). The Influence of using Read Imagine Describe Evaluate Repeat (RIDER) Strategy towards Students' Reading Comprehension in Descriptive Text at the First Semester of the Tenth Grade of Ma Raudlatul Mutta'allimin Kasui Way Kanan In The Academic Year 2018/2019. (Unpublished Ph.D. dissertation). Universitas Islam Negeri Raden Intan Lampung, Indonesia.

Free, W. P. (2004). Pictures and Words Together: Using Illustration Analysis and ReaderGenerated Drawings to Improve Reading Comprehension. Ph.D. Dissertation, Department of Art Education, The Florida State University.

Gambrell, L. B. (1982). Induced mental imagery and the text prediction performance of first and third graders. In J. A. Niles \& L. A. Harris (Eds.), New Inquiries in Reading Research and Instruction. Thirty-first yearbook of the National Reading Conference (pp. 131135). Rochester: National Reading Conference.

Ganis, G., \& Schendan, H. E. (2011). Visual imagery. Wiley Interdisciplinary Reviews: Cognitive Science, 2(3), 239-252.

Hibbing, A. N., \& Rankin-Erickson, J. L. (2003). A picture is worth a thousand words: using visual images to improve comprehension for middle school struggling readers. The Reading Teacher, 56, 758-771.

Israel, S. E., \& Duffy, G. G. (2014). Handbook of research on reading comprehension.(Eds.). Routledge.

Johnson-Glenberg, M. C. (2000). Training reading comprehension in adequate decoders/poor comprehenders: verbal vs visual strategies. Journal of Educational Psychology, 92, 772-782.

Kendeou, P., Van Den Broek, P., Helder, A., \& Karlsson, J. (2014). A cognitive view of reading comprehension: Implications for reading difficulties. Learning disabilities research \& practice, 29(1), 10-16.

Kolb, D. A. (2014). Experiential learning: Experience as the source of learning and development. FT press.

Levstik, L., \& Barton, K. (2015). Doing History: Investigating with Children in Elementary and Middle Schools. New York, London: Routledge.

Lin, X. (2020). An Evaluation of Visualization Activities' Effectiveness in EFL Reading. In 6th International Conference on Education, Language, Art and Inter-cultural Communication (ICELAIC 2019) (pp. 131-133). Atlantis Press.

Mackey, M. (2019). Visualization and the Vivid Reading Experience. Jeunesse: Young People, Texts, Cultures, 11(1), 38-58.

Makarova, E. A., Makarova, E. L., \& Varaksa, A. M. (2017). Education process visualization in metacognition development and sustainability. International Journal of Cognitive Research in Science, Engineering and Education, 5(2), 65.

Mayer, R. E. (1997). Multimedia learning: Are we asking the right questions? Educ. Psychol. 32: 1-19.

Mercer, C. D., \& Mercer, A. R. (2006).Teaching Students with Learning Problems. Englewood Cliffs, New Jersey: Prentice-Hall.

Moore, B. H., and Caldwell, H. (1993). Drama and drawing for narrative writing in primary grades. J. Educ. Res. 87: 100-110. 
Moriyanti, M., Muna, H., \& Ismail, N. M. (2019). Visualization and comprehension: Corroborating children's reading ability. Englisia: Journal of Language, Education, and Humanities, 7(1), 26-40.

Naug, H. L., Colson, N. J., \& Donner, D. (2016). Experiential Learning, Spatial Visualization and Metacognition: An Exercise with the "Blank Page" Technique for Learning Anatomy. Health Prof Educ; 2: 51-7.

Oakhill, J., Cain, K., \& Elbro, C. (2019). Reading comprehension and reading comprehension difficulties. In Reading Development and Difficulties (pp. 83-115). Springer, Cham.

Poushaneh, K., \& Azar, B. F. G. (2020). The Effect of Mental Imagery Strategy Instruction on Reading Comprehension of EFL Students. Curriculum Research, 1(2), 38-46.

Roe, B. D., Smith, S. H., \& Kolodziej, N. (2019). Teaching Reading in Today's Elementary Schools. $12^{\text {th }}$ Ed. Boston, USA: Cengage Learning.

Rubman, C. N., \& Waters, H. S. (2000). A, B seeing: The role of constructive processes in children's comprehension monitoring. Journal of Educational Psychology, 92(3), 503.

Sadoski, M. (1985). 'The natural use of imagery in story comprehension and recall: replication and extension'. Reading Research Quarterly, 20: 658-67.

Sanati, Z. (2020). The Effects of Visualization Training Techniques on Reading Comprehension Ability of Iranian Intermediate EFL Learners. Journal of Language Teaching and Research, 11(1), 73-85.

Schnotz, W. (2002). Commentary: Towards an integrated view of learning from text and visual displays. Educational psychology review, 14(1), 101-120.

Schmidgall, S. P., Eitel, A., \& Scheiter, K. (2018). Why do learners who draw perform well? Investigating the role of visualization, generation and externalization in learnergenerated drawing. Learning and Instruction, 60, 138-153.

Van Meter, P., \& Firetto, C. (2013). Cognitive model of drawing construction. Learning through the construction of drawings. In G. J. Schraw, M. T. McCrudden, \& D. Robinson (Eds.), Learning through visual displays. Charlotte, NC: Information Age Publishing.

Wood, K. D. (2002). Aiding comprehension with the imagine, elaborate, predict, and confirm (IEPC) strategy. Middle School Journal, 33(3), 47-54. 